\title{
Article
}

Mycosphere

\section{Nomenclatural and identification pitfalls of endophytic mycota based on DNA sequence analyses of ribosomal and protein genes phylogenetic markers: A taxonomic dead end?}

\author{
Jeewon $\mathrm{R}^{1}$, Wanasinghe $\mathrm{DN}^{2}$, Rampadaruth $\mathrm{S}^{3}$, Puchooa $\mathrm{D}^{3}$, Li-Gang Zhou ${ }^{4}$, Ai- \\ Rong Liu ${ }^{5}$, Hong-Kai Wang6* \\ ${ }^{1}$ Departmental of Health Sciences, Faculty of Science, University of Mauritius, Reduit, 80837, Mauritius. \\ ${ }^{2}$ Center of Excellence in Fungal Research, Mae Fah Luang University, Chiang Rai 57100, Thailand \\ ${ }^{3}$ Faculty of Agriculture, University of Mauritius, Reduit, 80837, Mauritius. \\ ${ }^{4}$ College of Agronomy and Biotechnology, China Agricultural University, Beijing 100193, P. R. China \\ ${ }^{5}$ College of Forestry, Henan University of Science and Technology, Luoyang 471003, China. \\ ${ }^{6}$ Biotechnology Institute, Zhejiang University, Hangzhou 310058, P. R. China.
}

Jeewon R, Wanasinghe DN, Rampadaruth S, Puchooa D, Zhou Li-Gang, Liu Ai-Rong, Wang HongKai 2017 - Nomenclatural and identification pitfalls of endophytic mycota based on DNA sequence analyses of ribosomal and protein genes phylogenetic markers: A taxonomic dead end? Mycosphere 8(10), 1802-1817, Doi 10.5943/mycosphere/8/10/7

\begin{abstract}
Fungal endophytes are considered ecologically important microorganisms, but their role is the subject of much speculation and the methods and approaches by which endophytes are detected and identified give rather different results. In this study, we isolated a specific endophyte from a traditional medicinal plant and investigated its phylogenetic relationships with other known fungi. Microscopic examination and cultural details of the strain are documented, but these did not provide adequate data to substantially identify the species, either to a genus or species level. To overcome this limitation, six different gene regions (SSU, LSU, ITS, TEF, RBP2 \& $\beta$-Tubulin) were amplified, sequenced and analysed phylogenetically (either in individual or concatenated datasets) to identify and investigate the placement of this endophyte at different taxonomic ranks. Results obtained from the cultural morphology were insufficient to identify the species. DNA sequence analyses (either single gene or combined gene analyses) revealed that this endophyte belongs to the order Pleosporales, class Dothideomycetes. However, an accurate establishment of its generic or even familial position is unresolved and the problems associated with our current system of assigning endophytes to a particular rank are discussed
\end{abstract}

Key words - Dioscorea zingiberensis - endophyte - multigene phylogeny - Pleosporales - taxonomy

\section{Introduction}

Endophytes have long been recognized as an integral part of the plant microflora without apparently causing disease symptoms (Hyde \& Soytong 2008). Their presence contributes positively 
to the well-being of plants (Promputtha et al. 2010, Dudeja et al. 2012) and they are widely known for their pharmaceutical and biotechnological importance (Li et al. 2008, Strobel et al. 1996, Refaei et al. 2011, Torres \& Dela Cruz 2015). The cosmopolitan nature of endophytes is widely recognized and most plant species investigated so far have been reported to be associated with endophytes (Guo et al. 2003, Jeewon et al. 2004, Kumar \& Hyde 2004, Promputtha et al. 2007, Huang et al. 2008, Shankar \& Shashikala, 2010). From a phylogenetic perspective, endophytes are taxonomically highly diverse and have been found to belong to different fungal lineages (Promputtha et al. 2005, 2007, Jeewon et al. 2013). There still remains a major difficulty in the identification of endophytes (Ko et al. 2011). Most studies relied heavily on traditional microscopy and cultural methods, but these have shown to be inadequate to correctly estimate diversity or identify species and hence their putative evolutionary relationships with known fungi remain largely elusive (Jeewon \& Hyde 2007, Hyde \& Soytong, 2007). Most isolates recovered fail to sporulate in culture and are considered as mycelia sterilia (e.g Lacap et al. 2003). To date, one of the most reliable and widely used techniques to putatively identify those mycelia sterilia or assign them to established genus or species is through DNA sequencing and analysis. In short, DNA is extracted, part of a well-known gene is amplified and sequenced and eventually analysed phylogenetically to determine their fungal relatives.

Traditional medicinal plants in China are rich and reliable sources of novel endophytic fungi (Liu et al. 2010, 2012). Among them Dioscorea zingiberensis, a traditional Chinese medicinal plant has been shown to produce diosgenin, an important precursor of semi-synthetic steroids such as corticosteroids, sex hormones and other steroidal drugs as well as beauvericin which demonstrated antibacterial activity (Xu et al. 2010, Zhu et al. 2010). In the pursuit of natural products from endophytic fungi isolated from this host, a strange and unidentified endophytic strain was isolated. It produced unidentified types of conidia under cultural conditions (resembling chlamydospores) and this study aims at clarifying its taxonomic identity based on microscopy, cultural studies as well as infer its ordinal and familial placement based on DNA sequence analyses of six gene regions. The pitfalls with regards to identification and classification of endophytes are also highlighted.

\section{Materials \& Methods}

\section{Fungal isolation}

Healthy rhizomes of Dioscorea zingiberensis were collected from Hubei Province of China and surface sterilized by swabbing the surface with cotton wool dipped in $75 \%$ ethanol and exposed to an alcohol flame for five seconds (as described by Duong et al. 2006). The outer layers of tissues were removed by a flame-sterilized scalpel and small pieces of inner tissues were cut, immersed in $70 \%$ ethanol for 1 minute, then soaking the tissue into $3 \% \mathrm{NaClO}$ solution for 1 minute, followed by rinsing in sterile distilled water for 3 times to wash out the bleach solution. After air-drying, the sterilized tissues were cut into small pieces using a flame-sterilized scalpel and placed onto water agar $\left[1 \%\right.$ agar in water] plates and incubated at $25^{\circ} \mathrm{C}$ for 7 days. A portion of mycelium developing on the water agar medium from the tuber pieces were transferred to new PDA plates to allow colonel growth and storage for further examination. The microscopic features of the fungus were observed after the pure culture was obtained. The cultures of endophytic fungal isolate Dzf12 have been deposited at the China General Microbiological Culture Collection Center (CGMCC) under acquisition number CGMCC 2476.

\section{Morphological and cultural studies}


Fungal isolate Dzf12 was grown on six different media including corn meal agar [CMA], malt agar [MA], potato dextrose agar [PDA], water agar [WA] (Boehm et al. 2009, Worapong et al. 2001), oatmeal agar [OMA] and complete media $\left[\mathrm{CM}\right.$ ], and was incubated at $25^{\circ} \mathrm{C}$ for one week. Cultural characterization of the colony morphologies was recorded on different media. The fungus was also inoculated onto Petri-dishes containing water agar with the sterile small pieces of wood shavings from host tree, or other plants such as apple [Malus pumila], pear [Pyrus communis], and tulip [Tulipa gesneriana] to encourage spore production. Microscopic morphological features of the fungal structures mounted in distilled water were observed by using an Olympus BX51 microscope fitted with a digital camera. The obtained photomicrographs were further edited using Adobe Photoshop.

\section{DNA extraction, amplification and sequencing}

Fungal isolate Dzf12 was grown on PDA plate for one week at $25^{\circ} \mathrm{C}$. The mycelia of colony were scraped by a sterilized toothpick and transferred to a $1.5 \mathrm{ml}$ Eppendorf tube, and genomic DNA was extracted using CTAB following methods outlined by Jeewon et al. (2002) \& Suwannarach et al. (2010). All amplification reactions for PCR were performed with $50 \mu \mathrm{l}$ reaction volume composing: $1 \times \mathrm{PCR}$ buffer, $0.2 \mathrm{mM}$ dNTP, $0.5 \mathrm{mM}$ of each primer, $2 \mathrm{mM} \mathrm{MgCl} 2,1.5$ units Taq polymerase and 5 10 ng genomic DNA. PCR thermal cycle parameters for all DNA fragments amplification was as follows: $94^{\circ} \mathrm{C}$ for $3 \mathrm{~min}$, followed by 34 cycles of denaturation at $94^{\circ} \mathrm{C}$ for $30 \mathrm{~s}$, annealing at $52^{\circ} \mathrm{C}$ for $1 \mathrm{~min}$, and elongation at $72^{\circ} \mathrm{C}$ for $1.5 \mathrm{~min}$ (Wang et al. 2007). The ITS regions were amplified using the universal primer pair ITS4 and ITS5 and the 18S and 28S rDNA genes were amplified using the universal primer pair NS1 and NS4 and primer pair LR0R and LR5 respectively (White et al. 1990) with PCR profiles as outlined by Jeewon et al. (2003). Three protein coding genes were also amplified, sequenced and analysed in this study. The RPB2 gene fragment was amplified with primer pair RPB2-5f and RPB2-7cr with profiles described by Senanayake et al. (2017). The primer pair TEF1983 and 2218R was used to amplify the translation elongation factor$1 \alpha$ [TEF1] (Schoch et al. 2009) with PCR profiles outlined by Luo et al. (2017). The tubulin gene fragment was amplified with primer pair BT2Fw and BT4Rd (Aveskamp et al. 2010). PCR products were purified using the PCR cleaning Kit according to the manufacturer's protocols [Sangon Bio., $\mathrm{CA}$ ]. The primers mentioned above were used for bidirectional DNA sequencing using Applied Biosystem 3730 XL DNA analyzer. Other sequences used in the analyses (Fig. 3, 4, 5 and 6) were obtained from GenBank based on blast searches in GenBank and recently published data in Hashimoto et al. (2017). The multiple alignments of all consensus sequences, as well as the reference sequences were automatically generated with MAFFT v. 7 (http://mafft.cbrc.jp/alignment/ serverindex.html; Katoh \& Standley 2013), and were improved manually when necessary using BioEdit v. 7.0.5.2 (Hall 1999). Ambiguous regions were excluded from the analyses and gaps were treated as missing data. Sequences have been submitted to GenBank as; $\beta$-Tubulin: JQ818138, ITS: EU543255, LSU: JQ818141, RBP2: JQ818140, SSU: JQ818142 and TEF: JQ818139.

\section{Phylogenetic analysis}

Phylogenetic analyses of both individual and combined aligned data were performed under maximum-likelihood. For the Randomized Accelerated Maximum Likelihood (RAxML) analysis, sequence alignments were converted to PHYLIP file (.phy) using ALTER (alignment transformation environment: http://Sing.ei.uvigo.es/ALTER/; 2017). Maximum likelihood trees were generated using the RAxML-HPC2 on XSEDE (8.2.8) (Stamatakis et al. 2008, Stamatakis 2014) in the CIPRES Science Gateway platform (Miller et al. 2010) using GTR $+\mathrm{I}+\mathrm{G}$ model of evolution. Six different gene 
datasets from the respective gene regions were also used for maximum-parsimony $[\mathrm{MP}]$ analysis, in which searches for most parsimonious trees were conducted with the heuristic search algorithm with tree-bisection-reconnection [TBR] branch swapping in PAUP* 4.0b4b (Swofford 2002). Other details are outlined in Jeewon et al. (2002) and Tang et al. (2009).Phylograms were visualized with FigTree v1.4.0 program (Rambaut 2012) and reorganized in Microsoft power point (2007) and Adobe Illustrator ${ }^{\circledR}$ CS5 (Version 15.0.0, Adobe ${ }^{\circledR}$, San Jose, CA).

\section{Results}

\section{Taxonomic description and cultural morphology}

Collections were made in Wuhan $\left[114^{\circ} 16 \square \mathrm{E}, 30^{\circ} 34 \square \mathrm{N}_{\mathrm{N}}\right.$ in Hubei Province, P. R. China by Jiaru Li of Wuhan University. The strain [coded as Dzf12] comes from a healthy rhizome of Dioscorea zingiberensis C.H. Wright [Dioscoreaceae]. The dried culture [BSMPMI-200506001] has been deposited in the Herbarium of the College of Agronomy and Biotechnology, China Agricultural University. The living culture has been deposited under the number CGMCC 2476 in

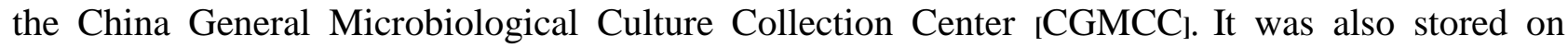
potato dextrose agar $\left[\mathrm{PDA}_{\text {] }}\right.$ slants at $4{ }^{\circ} \mathrm{C}$ and in $40 \%$ glycerol at $-70^{\circ} \mathrm{C}$ in the lab of Biology of Secondary Metabolism in Plant-Microbe Interactions [BSPMI] of China Agricultural University.

Spores and other fruiting bodies did not develop fully despite using different media and sterile plant parts. Conidiomata were sporodochial and aggregated, and formed microsclerotia. Conidiophores were micronematous and indistinct (Fig. 1). Conidiogenous cells were holoblastic, terminal or intercalary, thick-walled and smooth (Fig. 1). Conidia were staphylosporous to muriform, septate, abundant, thick-walled, dark brown, densely distributed throughout the colony (Fig. 1). Colonies slow growing, slightly raised, with circular margin, light to grayish brown, attaining $9 \mathrm{~cm}$ diameter in 3 weeks on PDA. Mycelium composed of partly immersed, partly superficial, septate, branched and smooth. Hyphae 1.6-4.5 $\mu \mathrm{m}$ wide and straight with sparse branching (Fig. 2). Aerial hyphal growth was abundant on PDA media supplemented with on sterile wood (Fig. 2).

The ITS dataset consisted of 78 taxa with 629 sites and phylogenies generated under different optimality criteria resulted in trees which were congruent in topology. The maximum likelihood tree with Murilentithecium clematidis as the outgroup is shown Fig. 3 [-Log likelihood of 5404.7019810]. The search for similar ITS sequences in GenBank showed that our strain has high sequence similarities and a close phylogenetic relatedness with two unidentified fungal species [FJ612674 \& GU187881] with high bootstrap support [Fig. 3] and this subclade is sister to another subclade consisting of Phoma nebulosa. There were 1354 characters which were analysed in the LSU dataset. Due to numerous unresolved branches with a large taxon sampling [over 100 taxa in the dataset], we limited our taxon sampling to only 95 taxa including Murilentithecium clematidis as the outgroup. Our endophyte Dzf12 clustered with Lophiotrema bambusae with no support in the family Lophiotremataceae as shown in a ML tree [-Log Likelihood of 5739.135, Fig. 4]. An identical topology with respect to the position of our endophyte was obtained from a combined SSU+LSU phylogeny (results not shown). The SSU matrix analysed in this study had 841 characters, 26 taxa [Diplodia corticola outgroup] and the maximum likelihood tree had a Log Likelihood of -2605.74 [results not shown]. Maximum parsimony analyses yielded two trees that were similar in topology. Isolate Dzf12 clusters with Zopfia rhizophila and together they formed a sister clade without strong support to Caryospora, Lepidosphaeria and Berkleasmium.

Sequences from TEF regions showed that isolate Dzf12 had high similarities with Hermatomyces species and phylogenetic analyses also revealed that isolate Dzf12 is closely related 
to Hermatomyces species (Hermatomycetaceae), but this relationship receives no support as in the case for LSU and LSU+SSU phylogenies [results not shown]. Analysis of a dataset of 22 taxa with Leptosphaeria maculans as the outgroup and 931 characters from the RPB2 gene region resulted in one parsimonious tree which was identical to the ML tree [Log Likelihood of -9244.68; results not shown]. Isolate Dzf12 was found to be basal to a clade consisting of Roussoella pustulans, $R$. hysterioides and Roussoellopsis tosaensis, but this relationship is poorly supported. ML analyses of the Beta Tubulin dataset which consisted of 26 taxa including Leptosphaeria maculans as the outgroup, yielded only a single parsimonious tree and a ML tree (-log likelihood 70001.35) which indicates a close relationship of our endophytic isolate to Sporormiella leporina, Herpotrichia juniper, Preussia typharum and Westerdykella dispersa [results not shown]. Maximum likelihood and Bayesian analyses of a combined LSU+SSU+TEF were also performed. Phylogeny generated indicates that isolate Dzf12 is basal to other members of Hermatomyces species (Hermatomycetaceae), but with no support (Fig. 5, same phylogenetic scenario as LSU and LSU+SSU phylogenies). Analyses of another larger concatenated dataset (LSU+SSU+TEF+ITS) basically yielded the same major clades as those derived from LSU+SSU+TEF, but the resulting tree provided a better statistical support for an affiliation of isolate Dzf12 with Hermatomyces species (Fig. 6). Other details pertaining to ML analyses of different datasets are summarised in Table 1. 

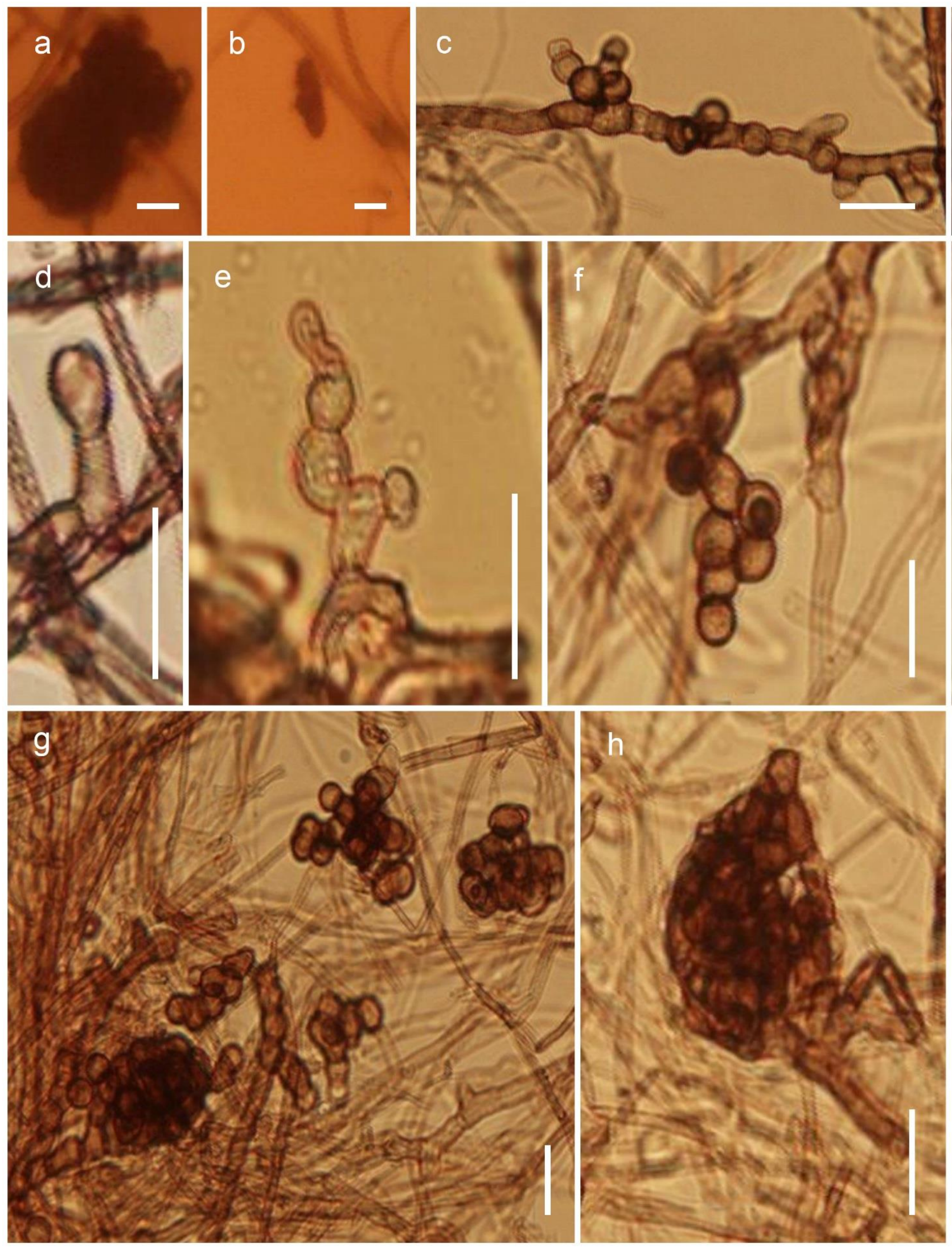

Figure 1 - Endophytic fungal strain Dzf12. a, b Sporodochia on colony. c-e Young conidia and conidiophores. f-h Mature conidia. Scale bars: $\mathrm{a}-\mathrm{h}=20 \mu \mathrm{m}$. 


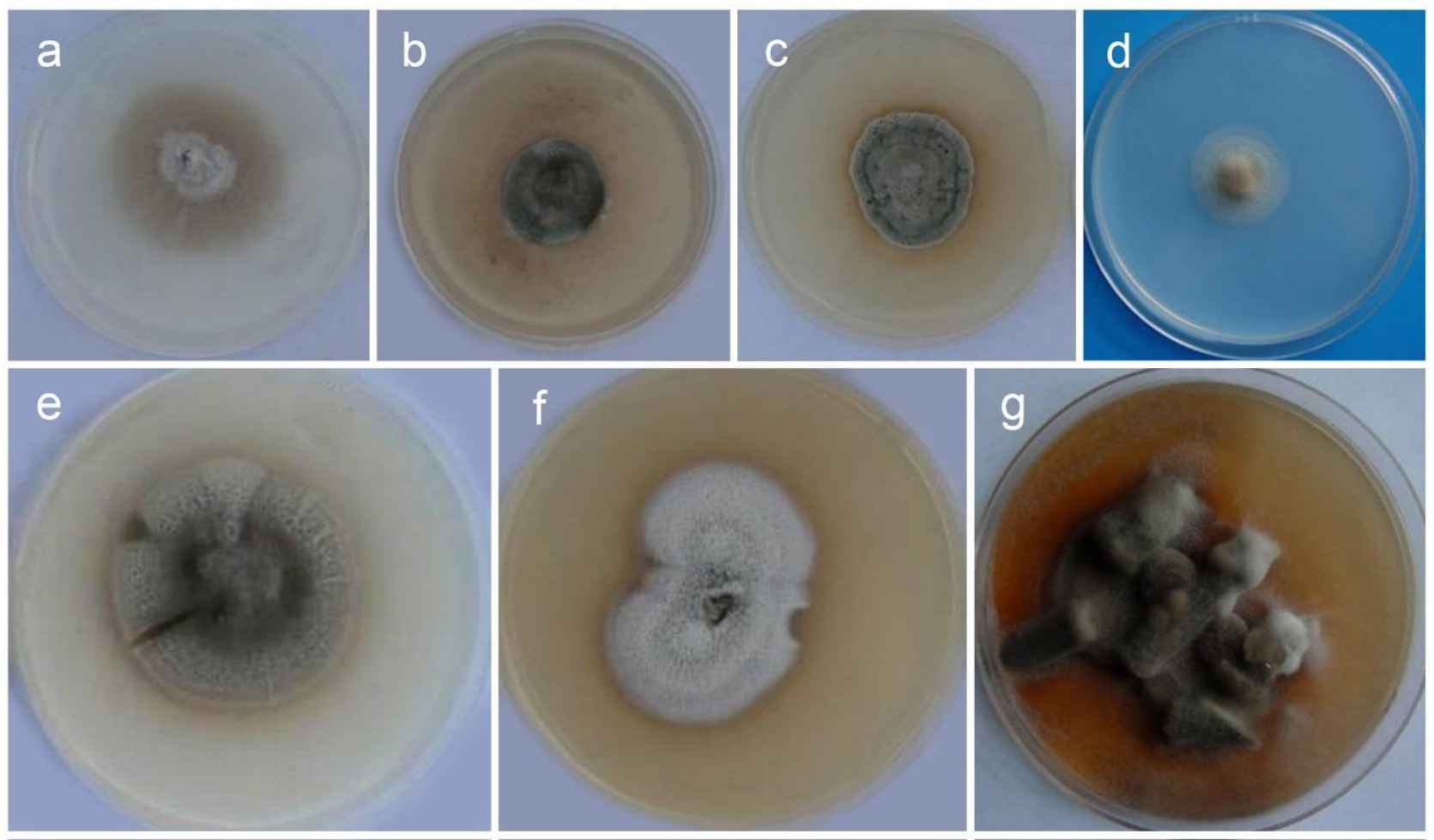

Figure 2-Cultural characteristics of endophytic fungal strain Dzf12 incubated on different media. a MEA. b PDA. c PCA. d WA. e OMA. f CM. g Wood.

Table 1 Comparison of ML analysis results for each sequence dataset in this study

\begin{tabular}{|c|c|c|c|c|c|}
\hline \multicolumn{2}{|l|}{ Dataset } & ITS & LSU & $\begin{array}{l}\text { Combined } \\
\mathbf{L S U}+\mathbf{S S U}+\mathbf{T} \\
\mathbf{E F}\end{array}$ & $\begin{array}{l}\text { Combined } \\
\text { LSU+SSU+TEF+ITS }\end{array}$ \\
\hline \multicolumn{2}{|l|}{ 1. Number of Taxa } & 78 & 95 & 95 & 95 \\
\hline \multicolumn{2}{|c|}{$\begin{array}{l}\text { 2. Number of character positions } \\
\text { (including gaps) }\end{array}$} & 629 & 1354 & 3311 & 3941 \\
\hline \multicolumn{2}{|c|}{ 3. ML optimization likelihood value } & -5404.7019810 & -5739.135 & -16611.312 & -22108.95951 \\
\hline \multicolumn{2}{|c|}{$\begin{array}{l}\text { 4. Distinct alignment patterns in the } \\
\text { matrix }\end{array}$} & 341 & 396 & 974 & 1298 \\
\hline \multicolumn{2}{|c|}{$\begin{array}{l}\text { 5. Number of undetermined characters } \\
\text { or gaps (\%) }\end{array}$} & 18.72 & 15.98 & 16.3 & 19.61 \\
\hline \multirow{4}{*}{$\begin{array}{l}\text { 6. Estimated base } \\
\text { frequencies }\end{array}$} & $\mathrm{A}$ & 0.24117 & 0.25153 & 0.24545 & 0.24495 \\
\hline & $\mathrm{C}$ & 0.27928 & 0.22403 & 0.24636 & 0.25053 \\
\hline & $\mathrm{G}$ & 0.24092 & 0.30263 & 0.27534 & 0.27104 \\
\hline & $\mathrm{T}$ & 0.23863 & 0.22180 & 0.23285 & 0.23348 \\
\hline \multirow{6}{*}{$\begin{array}{l}\text { 7. Substitution } \\
\text { rates }\end{array}$} & $\mathrm{AC}$ & 3.50871 & 1.14237 & 0.90995 & 1.65379 \\
\hline & $\mathrm{AG}$ & 2.75230 & 2.91987 & 2.93368 & 2.78001 \\
\hline & AT & 2.44284 & 0.94875 & 1.26788 & 1.57270 \\
\hline & CG & 0.92928 & 1.19182 & 1.32951 & 1.27366 \\
\hline & $\mathrm{CT}$ & 7.04974 & 15.83939 & 11.53083 & 10.00767 \\
\hline & GT & 1.00000 & 1.00000 & 1.00000 & 1.00000 \\
\hline \multicolumn{2}{|c|}{ 8. Proportion of invariable sites (I) } & 0.41423 & 0.53803 & 0.59626 & 0.56325 \\
\hline \multicolumn{2}{|c|}{$\begin{array}{l}\text { 9. Gamma distribution shape } \\
\text { parameter }(\alpha)\end{array}$} & 0.92070 & 0.51647 & 0.54217 & 0.52274 \\
\hline
\end{tabular}




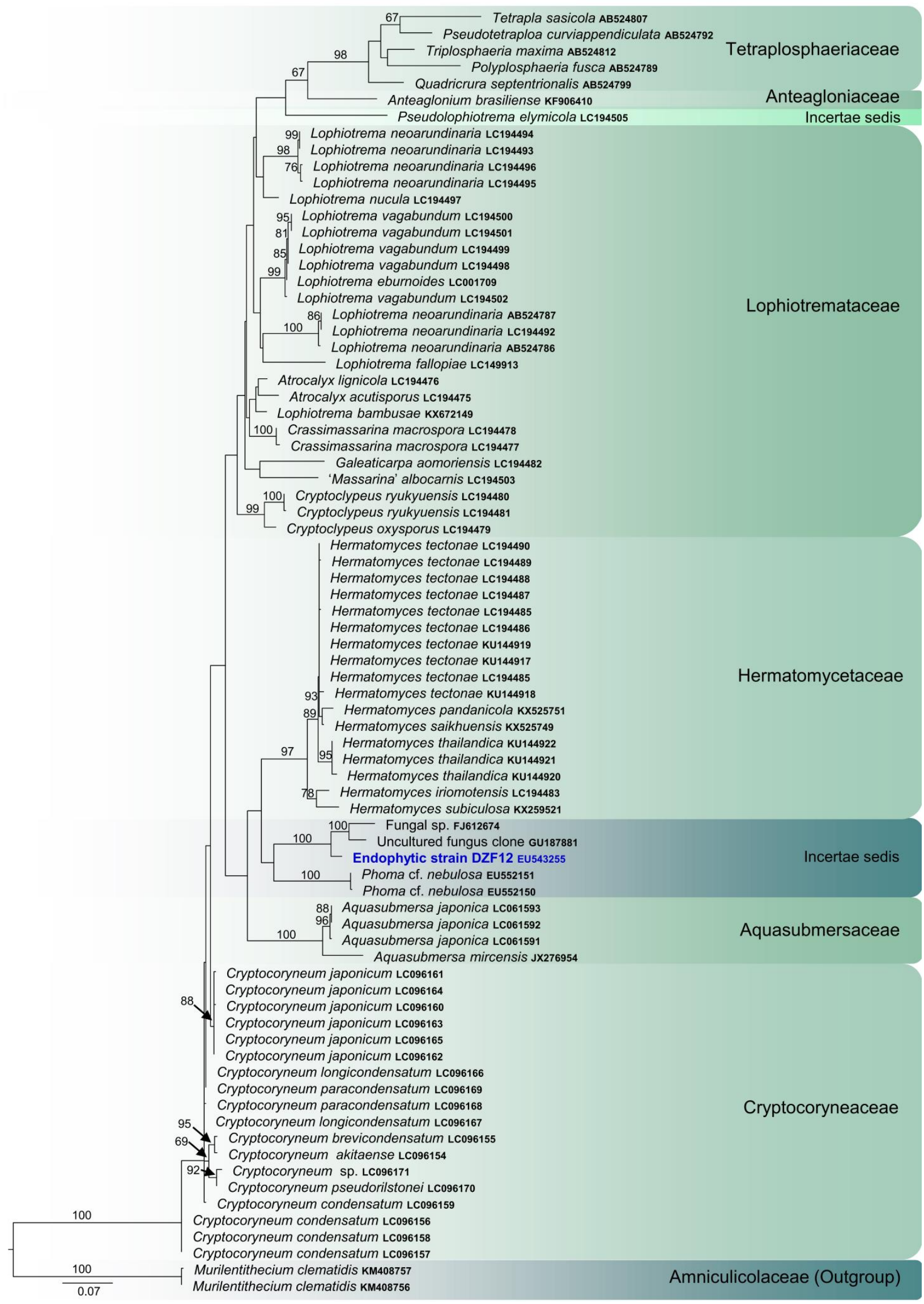


Figure 3 RAxML tree based on analysis of a dataset of ITS partial sequence data. Bootstrap support values for ML, higher than $60 \%$ are given above each branch respectively. The new isolate is in blue. The tree is rooted to Murilentithecium clematidis (Amniculicolaceae).

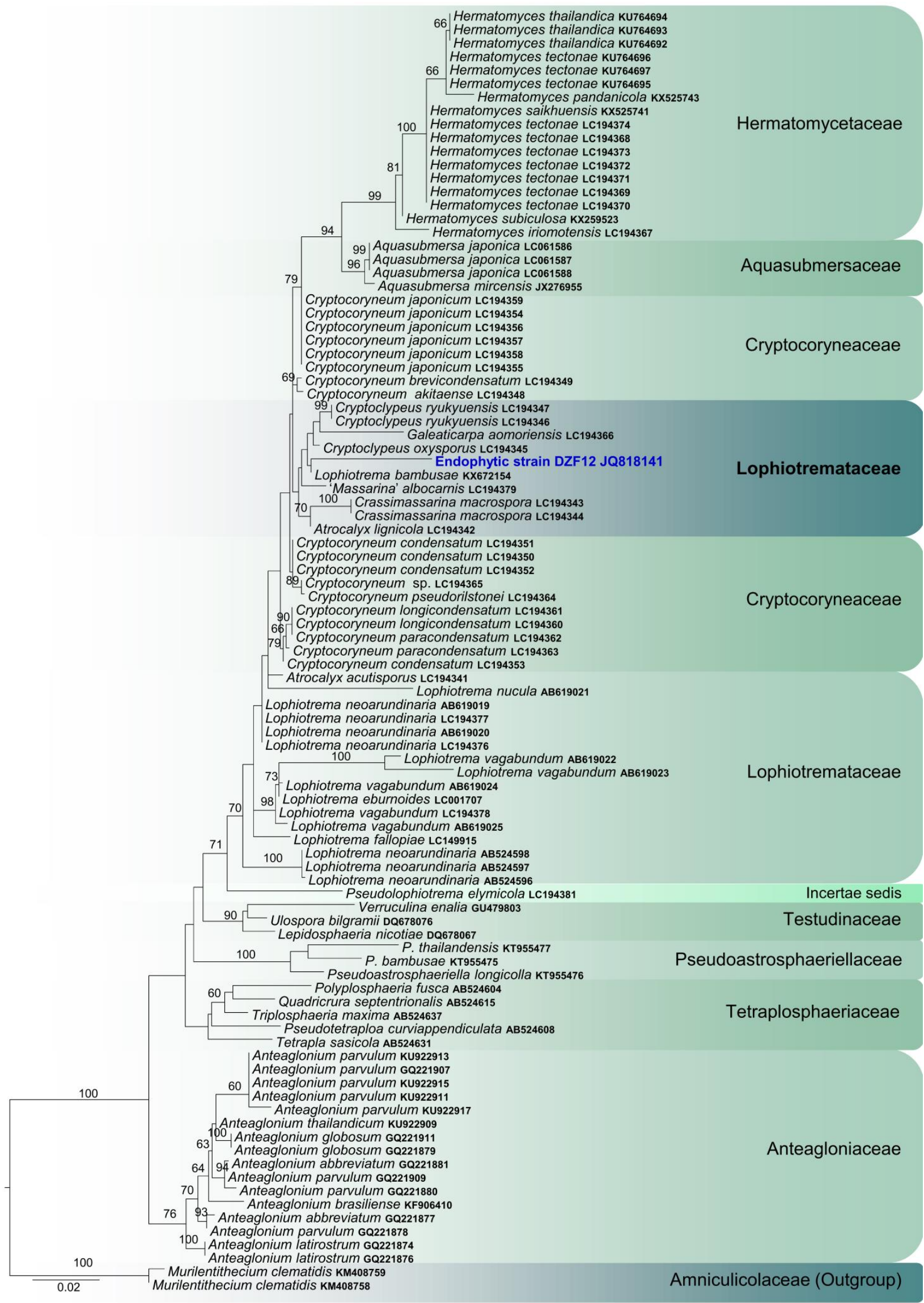


Figure 4 RAxML tree based on analysis of a dataset of LSU partial sequence data. Bootstrap support values for ML, higher than $60 \%$ are given above each branch respectively. The new isolate is in blue. The tree is rooted to Murilentithecium clematidis (Amniculicolaceae).

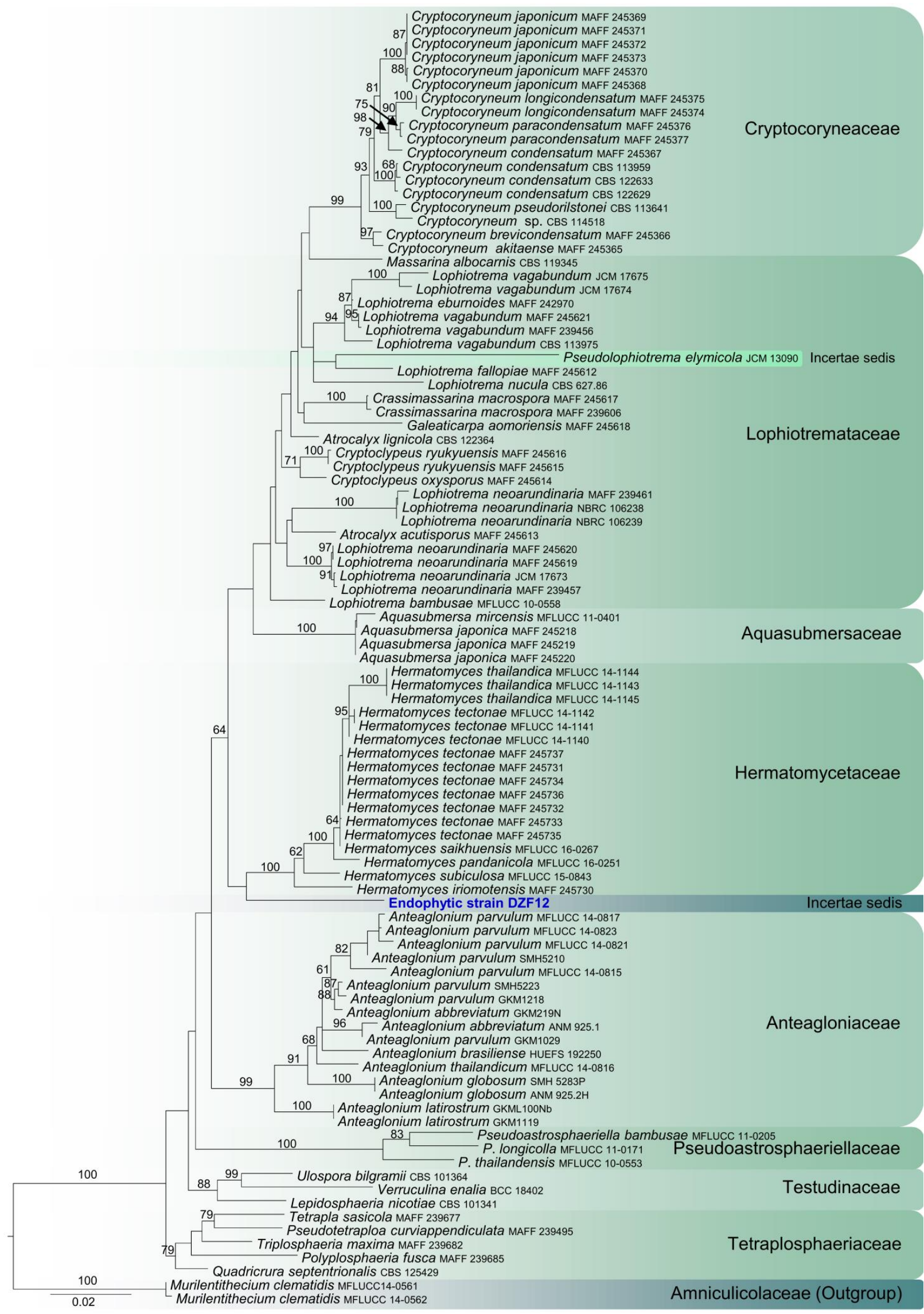


Figure 5 RAxML tree based on analysis of a combined dataset of LSU, SSU and TEF partial sequence data. Bootstrap support values for ML higher than $60 \%$ are given above each branch respectively. The new isolate is in blue. The tree is rooted to Murilentithecium clematidis (Amniculicolaceae).

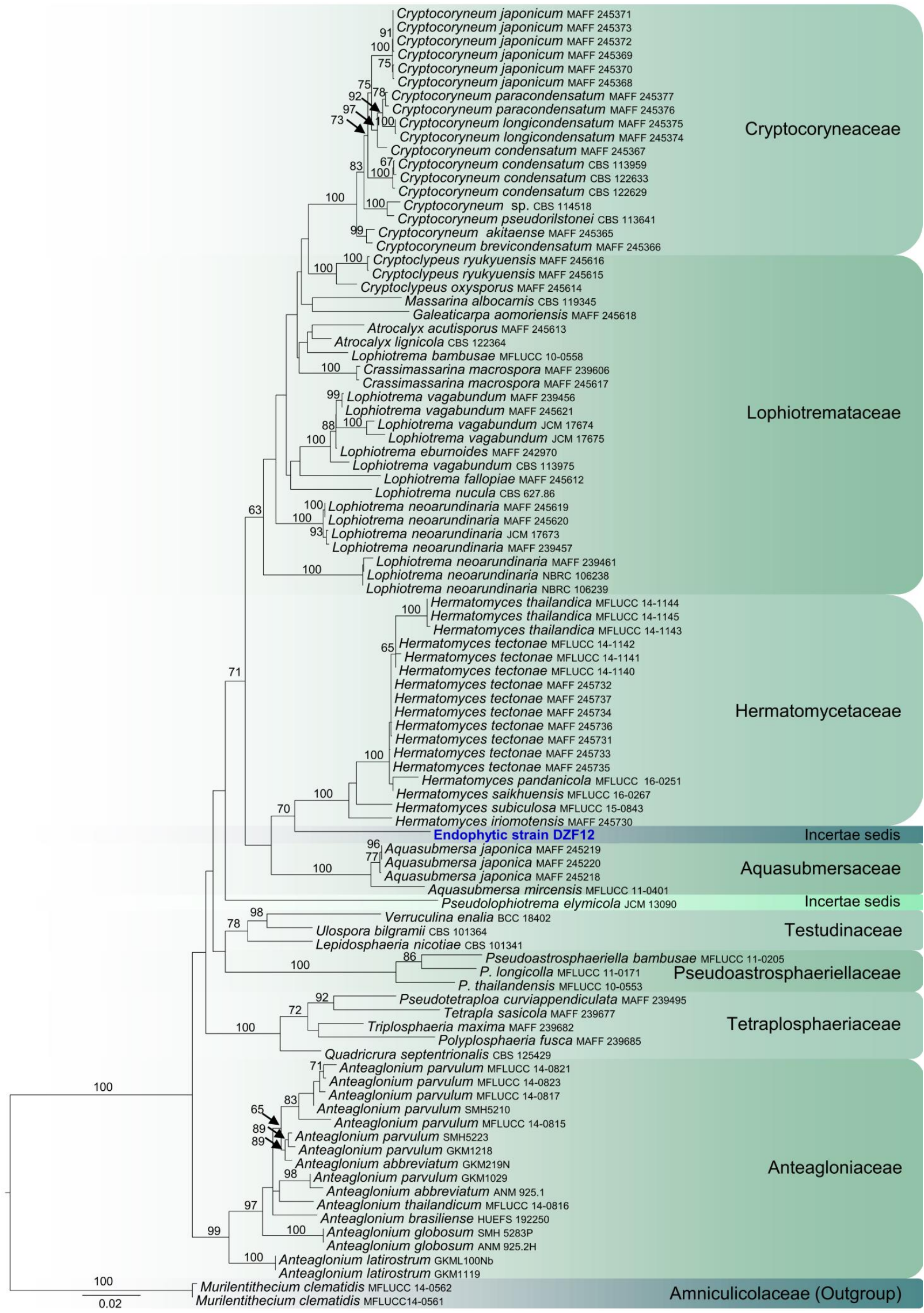


Figure 6 RAxML tree based on analysis of a combined dataset of LSU, SSU, TEF and ITS partial sequence data. Bootstrap support values for ML higher than $60 \%$ are given above each branch respectively. The new isolate is in blue. The tree is rooted to Murilentithecium clematidis (Amniculicolaceae).

\section{Discussion}

\section{Phylogeny and familial placement of Endophyte Dzf12}

ITS based phylogeny indicates that endophyte Dfz12 is closely related to two unidentified fungal species [FJ612674 \& GU187881] with high bootstrap support [Fig. 4] and this subclade is sister to another subclade characterized by Phoma species. A close relationship with fungal sp. [GenBank FJ612674] is not surprising as this is also an endophyte from seeds of Cecropia insignis (U'ren et al. 2009), but lacks morphological or cultural details and hence cannot be compared. A close connection with an uncultured fungus [GU187881] is also interesting, but there are disparities in morphology and cultural characteristics between our endophyte and Phoma especially in conidial or chlamydospore morphology. There are asexual morphs with chlamydospores within the Pleosporales (Shenoy et al. 2006, 2007, 2010; Jayasiri et al. 2016). For example, the genus Embellisia is characterized by proliferating chlamydospores and hyphal coils in culture and these are different from our morphological and cultural observations of our endophytic isolate. In addition, Embellisia has been accommodated in Pleosporaceae (Woudenberg et al. 2013) but our isolate was not phylogenetically related to any Pleosporaceae members as circumscribed by Tibpromma et al. (2017). LSU based phylogeny depicted a sister relationship of our endophyte with Lophiotrema bambusae and basal to Cryptoclypeus which are currently accommodated in the Lophiotremataceae [Fig. 4]. Lophiotrema bambusae is not a well-studied taxon with no known asexual morphs (Hyde et al. 2016) and its relationships to Atrocalyx is still obscure (Hashimoto et al. 2017). Of special interest was also a close phylogenetic connection between our isolate and other Lophiotremataceae members based on a combined LSU+SSU sequence data. Despite high sequence similarity in LSU and SSU gene sequences between endophyte Dzf12 and Lophiotrema, we reckon that any association of our endophyte with Lophiotrema species will be inconclusive unless sexual morph characters support such a connection and phylogenies are more resolved.

In addition, the asexual morphs of Lophiotrema are still unknown, but Lophiotrema nucula has been suggested to produce Pleurophomopsis asexual morphs, which are similar to those in Melanomma (Zhang et al. 2012)], but the isolate in this study did not form any Pleurophomopsis-like anamorphs. It would be wise if future studies could investigate the evolutionary relationships of Lophiotrema with the incorporation of terrestrial and marine samples, as well to elucidate whether this genus is more of an ecological group or taxonomic group. Further analyses confirmed that our endophyte isolate belonges to the Pleosporales, but an accurate and proper establishment into a family is still elusive. The association of our isolate with Zopfia rhizophila was not resolved in the SSU based sequence analysis [results not shown], and there was no support for the clade including Caryospora, Lepidosphaeria and Berkleasmium species. Zopfia and Caryospora belong to the family Zopfiaceae which is probably polyphyletic; Lepidosphaeria to the Testudinaceae, while Berkleasmium is an asexual morph and polyphyletic genus whose familial placement is still unresolved (Pinnoi et al. 2007; Wang et al. 2007; Tanner \& Miller 2017). The latter dictyosporous hyphomycete genus is also characterised by conidia having an inflated basal cell (Hüseyin et al. 2014), which is different from those asexual characters observed herein. Even using the RBP2 gene phylogeny to ascertain a familial placement of our endophyte is controversial. RBP2 based phylogeny reveals an association of endophyte Dzf12 to Roussoella pustulans and R. hysterioides, 
but the familial circumscription of this genus is still obscure. While it has been referred to the Massariaceae by Zhang et al. (2009), it has also been accommodated in Didymosphaeriaceae and recently to Roussoellaceae (Liu et al. 2014). To overcome potential bias associated with single gene analyses, we also combined two different datasets and performed phylogenetic analysis to check whether there is any incongruence in the phylogenies. Phylogeny of a concatenated dataset of the $\mathrm{LSU}_{+} \mathrm{SSU}+\mathrm{TEF}$ gene regions reveals that our endophyte is basal to other members of the Hermatomycetaceae as established by Hashimoto et al. (2017), but with no support (Fig 5). Further analyses based on the LSU+SSU+TEF+ITS gene regions resulted in a similar phylogenetic position, viz, within the Hermatomycetaceae, but with average support as compared to all other analyses where there was no support (Fig 6). The major problem we face herein is to provide an accurate familial position, leave alone a generic placement, of our isolate as we have recovered at least four different familial positions, which still needs to be resolved.

\section{Nomenclature of endophytes}

Mycologists are slowly moving away from the classical phenotypic approach based on morphological and cultural studies and most of our current fungal classification schemes rely heavily on the phylogenetic species concept based on multigene sequence analyses (e.g. Daranagama et al. 2016; Wanasinghe et al. 2017). But to what extent should a putative endophytic isolate or any other cryptic species be identified or delimited based DNA sequences or on clades arising from DNA sequence based phylogenies can be highly controversial (e.g Ko et al. 2011). Obviously, a close relationship between two taxa on a clade reven though with high bootstrap supporty does not mean that they should be considered conspecific as it could be artefacts of poor taxon sampling. Phylogeny in this study also highlights the major discrepancies and bias associated with the impact of taxon sampling on our phylogenetic inferences. Most of the clades recovered here that support an association between our endophyte and other taxa received poor bootstrap support, despite performing single gene or combined gene sequence analyses or increased taxon sampling. Under some circumstances, it has usually been considered that a 5\% sequence difference is adequate for establishing an OTU (e.g U'ren et al. 2009), while Jeewon \& Hyde 2016) recommended a minimum of $>1.5 \%$ nucleotide differences in the ITS regions. Taking into account both scenarios, we believe that our endophyte herein is not currently any known taxon of any described species with available sequences in GenBank. Another major impediment in the systematics of endophytes is the gaps in knowledge on asexual and sexual morph connections and Shenoy et al. 2007) have discussed the importance of DNA sequence-data on the taxonomy of anamorphic fungi.

A word of caution is therefore warranted when mycologists tentatively assign endophytes to specific genera and species. Despite having recovered some morphological characters from cultures and analysed nine different gene datasets here, we still refrain from naming or associate the isolate to any known species. It is common practice that phylogeneticists perform a blast search, rely on sequence similarity and capitalise on gene trees (especially on ribosomal DNA sequences) for species identity (e.g Sunayana et al. 2014, Raja et al. 2015). This can be quite erroneous as not all sequences from known species have been deposited in GenBank or some species could have been wrongly named. In addition, as observed for protein genes sequence analyses in this study, having high blast similarity and scores are no reflection of the true phylogeny of an organism. In this context, it is noteworthy that nomenclatural affiliation of endophytes should be assigned with extreme precaution from a taxonomic point of view. In addition, we also noted that limited or inappropriate sampling as well as the poorly resolved phylogenetic relationships makes it difficult to confidently establish an endophyte in a specific genus or species or even family. This taxonomic scenario is also common to many other endophytes and uncultured environmental samples, and 
even a number of them have been referred to as uncultured Pleosporales (Herrera et al. 2011).Of particular interest in this study are the ancestral relationships of this endophyte to other bitunicates fungi which are poorly documented (Slippers \& Wingfield 2007, Tao et al. 2008, Sunayana et al. 2014, Raja et al.2015, Cosoveanu et al. 2016).

We have noted major discrepancies in conventional ways of identifying endophytes and therefore believe that a major shift towards genotypic identification of sterile isolates is important and to date DNA based analyses can provide insights into their taxonomic placement as well as their evolutionary trend. Yet taxonomy of most endophytes is still problematic. Have mycologists reached a dead end with regards to interpretation of fungal genetic diversity from endophytes/OTU's and properly assign them to an appropriate taxonomic rank? The end point of this paper is the dilemma as whether to introduce this taxon as a new species? We have shown it is obviously a new species and have the culture and dried cultures which we can use for a holotype for valid publication. However, the morphology is barely adequate to introduce a new species, genus and even family, and the placement of the taxon is not clearly resolved. This is similar to the many OTU's resulting from studies using new generation sequencing (Peršoh 2015, Izuno et al. 2016). There are obviously several nomenclatural problems associated with Environmental Nucleic Acid Sequences (ENAS) under our current Code (Lücking \& Moncada 2017). The later advocate naming of ENAS despite constraints and also postulated some good practices should OTU's be formally described from environmental sequence data. However, herein since we have no idea what the fungus looks like and given that in most cases the phylogenies will be poorly resolved, we suggest this could be a wrong and dangerous approach. In conclusion we therefore do not introduce our new species due to lack of adequate data.

\section{Acknowledgements}

The authors wish to thank the financial support from the National Natural Science Foundation of China [31071710] and Natural Science Foundation of Zhejiang Province [No. LY15C140001], and also acknowledge Jiaru Li of Wuhan University of China to collect D. zingiberensis rhizomes. The University of Mauritius is acknowledged for assistance. Prof $\mathrm{J}$ Bhat is acknowledged for assistance in descriptions of asexual morphs from cultures.

\section{References}

Aveskamp MM, de Gruyter J, Woudenberg JHC, Verkley GJM et al. 2010 - Highlights of the Didymellaceae: A polyphasic approach to characterize Phoma and related pleosporalean genera. Studies in Mycology 65, 1-60.

Boehm E, Mugambi G, Miller A, Huhndorf S et al. 2009 - A molecular phylogenetic reappraisal of the Hysteriaceae, Mytilinidiaceae and Gloniaceae (Pleosporomycetidae, Dothideomycetes) with keys to world species. Studies in Mycology 64, 49-83.

Cosoveanu A, Cabrera R, Hernandez M, Iacomi-Vasilescu B et al. 2016 - Fungi as endophytes in Chinese Artemisia spp.: juxtaposed elements of phylogeny, diversity and bioactivity. Mycosphere 7, 102-117.

Daranagama A, Camporesi E, Jeewon R, Liu XZ et al. 2016 - Taxonomic rearrangement of Anthostomella (Xylariaceae) based on a multigene phylogeny and morphology. Cryptogamie Mycologie 37, 509-538.

Dudeja SS, Giri R, Saini R, Suneja-Madan P et al. 2012 - Interaction of endophytic microbes with legumes. Journal of Basic Microbiology 52, 248-260. 
Duong LM, Jeewon R, Lumyong S, Hyde KD. 2006 - DGGE coupled with ribosomal DNA phylogenies reveal uncharacterized fungal phylotypes on living leaves of Magnolia liliifera. Fungal Diversity 23, 121-138.

Guo LD, Huang GR, Wang Y, He WH et al. 2003 - Molecular identification of white morphotype strains of endophytic fungi from Pinus tabulaeformis. Mycological Research 107, 680-688.

Hall TA. 1999 - BioEdit: a user-friendly biological sequence alignment editor and analysis program for Windows 95/98/NT. Nucleic Acids Symposium Series No. 41, 95-98.

Hashimoto A, Matsumura M, Hirayama K, Tanaka K. 2017 - Revision of Lophiotremataceae (Pleosporales, Dothideomycetes): Aquasubmersaceae, Cryptocoryneaceae, and Hermatomycetaceae fam. nov. Persoonia 39, 51-73.

Herrera J, Poudel R, Khidir HH. 2011 - Molecular characterization of coprophilous fungal communities reveals sequences related to root-associated fungal endophytes. Microbial Ecology 61, 239-244.

Huang W, Cai Y, Hyde K, Corke H, Sun M. 2008 - Biodiversity of endophytic fungi associated with 29 traditional Chinese medicinal plants. Fungal Diversity 33, 61-75.

Hüseyin E, Selçuk F, Churakov BP. 2014 - A new species of Berkleasmium from Ulyanovsk, Russia. Mycosphere 5, 462-466.

Hyde KD, Soytong K. 2008 - The fungal endophyte dilemma. Fungal Diversity 33, 163-173.

Hyde KD, Hongsanan S, Jeewon, R et al. 2016 - Fungal diversity notes 367-491: taxonomic and phylogenetic contributions to fungal taxa. Fungal Diversity 80, 1-270.

Hyde KD, Soytong K. 2007 - Understanding microfungal diversity-a critique. Cryptogamie Mycologie, 28, 281-289.

Izuno A, Kanzaki M, Artchawakom T, Wachrinrat C et al. 2016 - Vertical Structure of Phyllosphere Fungal Communities in a Tropical Forest in Thailand Uncovered by High-Throughput Sequencing. PLoS ONE 11(11): e0166669.

Jayasiri SC, Hyde KD, Jeewon R, Bhat JD et al. 2016 - Neooccultibambusa jonesii, a novel taxon within Occultibambusaceae. Mycosphere 7, 1458-1472.

Jeewon R, Hyde KD. 2007 - Detection and diversity of fungi from environmental samples: traditional versus molecular approaches. Advanced Techniques in Soil Microbiology 1-15.

Jeewon R, Hyde KD. 2016 - Establishing species boundaries and new taxa among fungi: recommendations to resolve taxonomic ambiguities. Mycosphere 7, 1669-1677.

Jeewon R, Ittoo J, Mahadeb D, Jaufeerally-Fakim Y et al. 2013 - DNA based identification and phylogenetic characterisation of endophytic and saprobic fungi from Antidesma madagascariense, a medicinal plant in Mauritius. Journal of Mycology 2013, 1-10.

Jeewon R, Liew E, Hyde KD. 2004 - Phylogenetic evaluation of species nomenclature of Pestalotiopsis in relation to host association. Fungal Diversity 17, 39-55.

Jeewon R, Liew ECY, Simpson, JA, Hodgkiss, IJ et al. 2003 - Phylogenetic significance of morphological characters in the taxonomy of Pestalotiopsis species. Molecular Phylogenetics and Evolution 27,372-383.

Jeewon R, Liew ECY, Hyde KD. 2002 - Phylogenetic relationships of Pestalotiopsis and allied genera inferred from ribosomal DNA sequences and morphological characters. Molecular Phylogenetics and Evolution 25, 378-392

Katoh K, Standley DM. 2013 - MAFFT multiple sequence alignment software version 7: improvements in performance and usability. Molecular Biology \& Evolution 30, 772-780. 
Ko TKW, Stephenson SL, Bahkali AH, Hyde KD. 2011 - From morphology to molecular biology: can we use sequence data to identify fungal endophytes? Fungal Diversity 50, 113-120.

Kumar DSS, Hyde KD. 2004 - Biodiversity and tissue-recurrence of endophytic fungi in Tripterygium wilfordii. Fungal Diversity 17, 69-90.

Lacap DC, Hyde KD, Liew ECY. 2003 - An evaluation of the fungal 'morphotype' concept based on ribosomal DNA sequences. Fungal Diversity 12, 53-66.

Li J, Zhao GZ, Chen HH, Wang HB et al. 2008 - Antitumour and antimicrobial activities of endophytic streptomycetes from pharmaceutical plants in rainforest. Letters in Applied Microbiology 47, 574-580.

Liu A, Chen S, Jin W, Zhao P et al. 2012 - Host specificity of endophytic Pestalotiopsis populations in mangrove plant species of South China. African Journal of Microbiology Research 6, 62626269.

Liu A, Chen S, Lin X, Wu S et al. 2010 - Endophytic Pestalotiopsis species associated with plants of Palmae, Rhizophoraceae, Planchonellae and Podocarpaceae in Hainan, China. African Journal of Microbiology Research 4, 2661-2669.

Liu JK, Phookamsak R, Dai DQ, Tanaka K et al. 2014 - Roussoellaceae, a new pleosporalean family to accommodate the genera Neoroussoella gen. nov., Roussoella and Roussoellopsis. Phytotaxa 181, 1-33.

Lücking R, Moncada B. 2017 - Dismantling Marchandiomphalina into Agonimia (Verrucariaceae) and Lawreymyces gen. nov. (Corticiaceae): setting a precedent to the formal recognition of thousands of voucherless fungi based on type sequences. Fungal Diversity 84,119-138.

Luo ZL, Bhat JD, Jeewon R, Boonmee S et al. 2017 - Molecular phylogeny and morphological characterization of asexual fungi (Tubeufiaceae) from freshwater habitats in Yunnan, China. Cryptogamie Mycologie 38, 1-28.

Miller MA, Pfeiffer W, Schwartz T. 2010 - Creating the CIPRES science gateway for inference of large phylogenetic trees. Proceedings of the Gateway Computing Environments Workshop (GCE), November 14, 2010, New Orleans, Louisiana 1-8.

Peršoh D. 2015 - Plant-associated fungal communities in the light of meta'omics. Fungal Diversity $75,1-25$.

Pinnoi A, Jeewon R, Sakayaroj J, Hyde KD et al. 2007 - Berkleasmium crunisia sp. nov. and its phylogenetic affinities to the Pleosporales based on 18S and 28S rDNA sequence analyses. Mycologia 99, 378-84.

Promputtha I, Hyde KD, McKenzie EHC, John F et al. 2010 - Can leaf degrading enzymes provide evidence that endophytic fungi becoming saprobes? Fungal Diversity 41, 89-99.

Promputtha I, Jeewon R, Lumyong S, McKenzie E et al. 2005 -Ribosomal DNA fingerprinting in the identification of non-sporulating endophytes from Magnolia liliifera (Magnoliaceae). Fungal Diversity 20, 167-186.

Promputtha I, Lumyong S, Vijaykrishna D, McKenzie EHC et al. 2007- A phylogenetic evaluation of whether endophytes become saprotrophs at host senescence. Microbial Ecology 53, 579_590.

Raja HA, Kaur A, El-Elimat T, Figueroa M et al. 2015 - Phylogenetic and chemical diversity of fungal endophytes isolated from Silybum marianum (L) Gaertn. (milk thistle). Mycology 6, 827.

Rambaut A. 2012 -FigTree version 1.4.0. Available at http:/tree.bio.ed.ac.uk/software/figtree/ 
Refaei J, Jones EBG, Sakayaroj J, Santhanam J. 2011 - Endophytic fungi from Rafflesia cantleyi: species diversity and antimicrobial activity. Mycosphere 2, 429_447.

Schoch C, Crous PW, Groenewald JZ, Boehm E et al. 2009 - A class-wide phylogenetic assessment of Dothideomycetes. Studies in Mycology 64, 1-15.

Senanayake IC, Maharachchikumbura SSN, Jeewon R, Promputtha I et al. 2017 Morphophylogenetic study of Sydowiellaceae reveals several new genera. Mycosphere 8, 172 217.

Shankar NB, Shashikala J. 2010 - Diversity and structure of fungal endophytes in some climbers and grass species of Malnad region, Western Ghats, Southern India. Mycosphere 1, 265-274.

Shenoy BD, Jeewon R, Hyde KD. 2007 - Impact of DNA sequence-data on the taxonomy of anamorphic fungi. Fungal Diversity 26, 1-54.

Shenoy BD, Jeewon R, Wang H, Amandeep K et al. 2010 - Sequence data reveals phylogenetic affinities of fungal anamorphs Bahusutrabeeja, Diplococcium, Natarajania, Paliphora, Polyschema, Rattania and Spadicoides. Fungal Diversity 44, 161-169.

Shenoy BD, Jeewon R, Wu WP, Bhat DJ et al. 2006 - Ribosomal and RPB2 DNA sequence analyses suggest that Sporidesmium and morphologically similar genera are polyphyletic. Mycological Research 110, 916-928.

Slippers B, Wingfield MJ. 2007. Botryosphaeriaceae as endophytes and latent pathogens of woody plants: diversity, ecology and impact. Fungal Biology Reviews 21, 90-106.

Stamatakis A, Hoover P, Rougemont J. 2008 - A rapid bootstrap algorithm for the RAxML web servers. Systematic Biology 57, 758-771.

Stamatakis A. 2014 - RAxML version 8: a tool for phylogenetic analysis and post-analysis of large phylogenies. Bioinformatics 30, 1312-1313.

Strobel G, Yang X, Sears J, Kramer et al. 1996 - Taxol from Pestalotiopsis microspora, an endophytic fungus of Taxus wallachiana. Microbiology 142, 435-440.

Sunayana N, Nalini MS, Sampath Kumara KK, Prakash HS. 2014 - Diversity studies on the endophytic fungi of Vitex negundo L. Mycosphere 5, 578-590.

Suwannarach N, Bussaban B, Hyde KD, Lumyong S. 2010 - Muscodor cinnamomi, a new endophytic species from Cinnamomum bejolghota. Mycotaxon 114, 15-23.

Swofford DL, Documentation B. 1991 - Phylogenetic analysis using parsimony. Illinois Natural History Survey, Champaign, IL.

Tang AMC, Jeewon R, Hyde KD. 2009 - A re-evaluation of the evolutionary relationships within the Xylariaceae based on ribosomal and protein-coding gene sequences. Fungal Diversity 34, 127 155 .

Tanner J, Miller AN. 2017 - Asexual-sexual morph connection in the type species of Berkleasmium. IMA Fungus 8, 99-105.

Tao G, Liu ZY, Hyde KD, Liu XZ. et al. 2008 - Whole rDNA analysis reveals novel and endophytic fungi in Bletilla ochracea (Orchidaceae). Fungal Diversity 33, 101-122.

Tibpromma S, Hyde KD, Jeewon R, Maharachchikumbura S. et al. 2017 - Fungal diversity notes 491602: taxonomic and phylogenetic contributions to fungal taxa. Fungal Diversity 83, 1-261.

Torres JMO, Dela Cruz TEE. 2015 - Antibacterial activities of fungal endophytes associated with the Philippine endemic tree, Canarium ovatum. Mycosphere 6, 266-273. 
U'ren JM, Dalling JW, Gallery RE, Maddison DR. 2009 - Diversity and evolutionary origins of fungi associated with seeds of a neotropical pioneer tree: a case study for analysing fungal environmental samples. Mycological Research 113, 432-449.

Wanasinghe DN, Hyde KD, Jeewon R, Crous et al. 2017. Phylogenetic revision of Camarosporium (Pleosporineae, Dothideomycetes) and allied genera. Studies in Mycology 87, 207-256.

Wang HK, Aptroot A, Crous PW, Hyde KD. et al. 2007 - The polyphyletic nature of Pleosporales: an example from Massariosphaeria based on rDNA and RBP2 gene phylogenies. Mycological Research 111, 1268-1276.

White TJ, Bruns T, Lee S, Taylor J. 1990 - Amplification and direct sequencing of fungal ribosomal RNA genes for phylogenetics. PCR protocols: a guide to methods and applications 18, 315-322.

Worapong J, Strobel G, Ford EJ, Li J. et al. 2001 - Muscodor albus anam. gen. et sp nov., an endophyte from Cinnamomum zeylanicum. Mycotaxon 79, 67-79.

Woudenberg J, Groenewald J, Binder M, Crous P. 2013 - Alternaria redefined. Studies in Mycology $75,171-212$

Xu L, Wang J, Zhao J, Li P. et al. 2010 - Beauvericin from the endophytic fungus, Fusarium redolens, isolated from Dioscorea zingiberensis and its antibacterial activity. Natural Products Communications 5, 811-814.

Zhang Y, Crous PW, Schoch CL, Hyde KD. 2012 - Pleosporales. Fungal Diversity 53, 1-221.

Zhang Y, Schoch CL, Fournier J, Crous et al. 2009 - Multi-locus phylogeny of Pleosporales: a taxonomic, ecological and evolutionary re-evaluation. Studies in Mycology 64, 85-102

Zhu Yl, Huang W, Ni JR, Liu W et al. 2010 - Production of diosgenin from Dioscorea zingiberensis tubers through enzymatic saccharification and microbial transformation. Applied Microbiology and Biotechnology 85, 1409-1416 